\title{
Expression and Purification of Recombinant Immunogenic Proteins of Goat Poxvirus in Prokaryotic System
}

\author{
Amit Kumar ${ }^{1 *}$, Gnanavel Venkatesan ${ }^{1}$, Anand Kushwaha ${ }^{1}$, P. Sasi Kumar ${ }^{1}$, \\ M.A. Ramakrishnan ${ }^{1}$ and Pronab Dhar ${ }^{2}$ \\ ${ }^{1}$ Division of Virology, ICAR-Indian Veterinary Research Institute, Mukteswar, \\ Uttarakhand, India \\ ${ }^{2}$ Division of Biological Standardization, ICAR-Indian Veterinary Research Institute, \\ Izatnagar, Uttar Pradesh, India \\ *Corresponding author
}

\section{A B S T R A C T}

\section{Keywords}

Capripoxvirus, Expression, F13L protein, Goatpox virus, $\mathrm{P} 32$ protein, Prokaryotic,

Western blot

Article Info

Accepted:

14 December 2018

Available Online:

10 January 2019
Capripox viruses of small ruminants, namely goatpox virus (GTPV) and sheep pox virus (SPPV) are responsible for important contagious diseases that are enzootic to the Indian sub-continent, Africa and the Middle East. In the present study, recombinant F13L and P32 proteins of GTPV were expressed in prokaryotic system, purified and confirmed in Western blot in order to evaluate their diagnostic potential. Full length F13L $\left({ }_{1} \mathrm{M}-\mathrm{L}_{370}\right.$ aa) and truncated P32 $\left({ }_{20} \mathrm{~V}-\mathrm{S}_{270}\right.$ aa) genes of GTPV-Uttarkashi strain were cloned into pET$33 \mathrm{~b}(+)$ vector, over-expressed in prokaryotic system and purified as histidine-tagged protein using Ni-NTA affinity chromatography under denaturing conditions and passive elution method, respectively. The recombinantF13Land P32 proteins lacked fusion tag from vector except histidine tag for purification as analyzed by SDS-PAGE. Expression was confirmed with Western blot using anti-GTPV serum. The purified recombinant F13L and P32 proteins can be used potential diagnostic antigen/s either individually or in combination for sero-diagnosis of capripox virus infections.

\section{Introduction}

Goatpox and sheeppox are contagious viral diseases of small ruminants endemic to Africa, the Middle-East and Asia including Indian subcontinent (Tuppurainen et al., 2017). These are associated with significant production losses due to high morbidity and mortality, decrease in weight gain, abortion and damage to wool and hides, which poses significant economic threats and trade restrictions for small ruminant industries in countries such as
India (Madhavan et al., 2016). The etiological agents, goatpox virus (GTPV) and sheeppox virus (SPPV) belong to Genus Capripoxvirus, family Poxviridae. Both viruses are serologically indistinguishable but can be differentiated using molecular techniques (Mirzaie et al., 2015). Generally, laboratory diagnosis of capripox infections is based on virus isolation, electron microscopy, serum neutralization test (SNT), counterimmunoelectrophoresis and molecular techniques (Bhanuprakash et al., 2011). SNT 
is considered to be a gold standard for serodiagnosis of capripox infections, but it is difficult to carry out and cannot detect low levels of antibodies in animals with mild disease or after vaccination. Although, whole virus antigen based indirect-ELISA assays were developed in the past (Sharma et al., 1988; Babiuk et al., 2009), the production of viral antigen in bulk is a major obstacle along with the risk of handling live virus. In view of productivity losses caused by capripox infection in animals, there is an imminent quest to design and develop recombinant protein based sero-diagnostic assays. In the past, few proteins of capripoxviruses have been expressed and evaluated for diagnostic potential (Heine et al., 1999; Bhanot et al., 2009; Bowden et al., 2009; Venkatesan et al., 2018), but no validated ELISA assay is available for sero-diagnosis of capripoxviruses. Poxviruses typically produce two infectious forms, namely extracellular enveloped virions (EEV) and intracellular mature virions (IMV) each with specific protein composition (Chung et al., 2006). The present study was envisaged to express F13L (extracellular enveloped virion/EEV protein) and P32 (intracellular mature virion/IMV protein) proteins of GTPV in prokaryotic system for further use as diagnostic antigen.

GTPV-Uttarkashi virus (Passage-60) maintained at Pox Virus Laboratory, Division of Virology, ICAR-IVRI, Mukteswar, India, was propagated in Vero cells and genomic DNA was extracted using QIAamp DNA Mini Kit (Qiagen, India). For F13L protein, primers targeting full length protein $\left({ }_{1} \mathrm{M}-\mathrm{L}_{370}\right.$ aa region) was designed (Table 1). Based on predicted presence of a signal sequence at $\mathrm{N}$ terminus and transmembrane domain at Cterminus of $\mathrm{P} 32$ gene, a set of primers targeting $\mathrm{N} \& \mathrm{C}$-terminal truncated $\mathrm{P} 32$ protein $\left({ }_{20} \mathrm{~V}-\mathrm{S}_{270}\right.$ aa region) were designed (Table 1$)$. The forward primer, and reverse primer had added restriction enzyme sites for $N c o$ I and
XhoI, respectively at 5' end along with primer tags.

The required primers were synthesized and procured (Europhins Genomics, India). PCR amplification was done using reaction mixture comprising 2x GoTaqPCR buffer (Promega, Germany), 10 pmol of each primer and template, with amplification conditions: initial denaturation at $95^{\circ} \mathrm{C}$ for $5 \mathrm{~min}$, followed by 35 cycles of denaturation at $94^{\circ} \mathrm{C}$ for $1 \mathrm{~min}$, annealing at $53^{\circ} \mathrm{C}$ for $1 \mathrm{~min}$, extension at $72^{\circ} \mathrm{C}$ for $1 \mathrm{~min}$, and a final extension at $72^{\circ} \mathrm{C}$ for $7 \mathrm{~min}$. The purified PCR products and pET$33 \mathrm{~b}(+)$ vector (Novagen, USA) were digested with $N c o I$ and XhoI restriction enzymes; and ligated recombinant plasmids were initially transformed into E. Coli Top 10F' strain. Each positive clone was confirmed by colony PCR using gene-specific primers described in Table 1 and restriction digestion with $\mathrm{Nco}$ I and Xho I enzymes for insert release. Further, recombinant plasmids from positive clones were transformed into expression host $E$. coli BL21-CodonPlus (DE3)-RIPL cells (Agilent Technologies, USA) and selected using antibiotics viz. kanamycin $(50 \mu \mathrm{g} / \mathrm{ml})$ and chloramphenicol $(35 \mu \mathrm{g} / \mathrm{ml})$.

E. coli BL21-CodonPlus (DE3)-RIPL cells harboring recombinant plasmid were grown on $250 \mathrm{ml}$ terrific broth containing appropriate antibiotics at $30^{\circ} \mathrm{C}$ to an O.D. of 0.4-0.6 before induction with $1 \mathrm{mM}$ IPTG and harvested at 6 $h$ post induction. The expressed recombinant proteins following lysis of harvested cells were checked for solubility analysis by analyzing both insoluble cellular fraction and soluble fraction obtained in the supernatant form through SDS-PAGE. The recombinant F13L protein was purified under denaturing conditions by affinity chromatography using Ni-NTA superflow cartridges (Qiagen, USA) at $300 \mathrm{mM}$ imidazole concentration as described earlier (Kumar et al., 2017). For P32 protein, which was difficult to purify by $\mathrm{Ni}$ - 
NTA affinity chromatography, protein purification by passive elution method was used as per the standard protocol (Yogisharadhya et al., 2018). After dialysis, protein aliquots were quantified using BCA protein assay kit (Pierce Technologies, USA) before storage at $-80^{\circ} \mathrm{C}$ until further use. For confirmation of recombinant proteins, induced/un-induced $E$. coli cultures were transferred onto nitrocellulose membrane using semi-dry immunoblot system (BenchTop Lab Systems, USA). Detection was carried out using 1:10 anti-GTPV polyclonal hyperimmune serum raised in goats as primary antibody and 1:12,000 diluted antigoatIgG horseradish peroxidase (HRPO) conjugate (Sigma, USA) as secondary antibody before developing a blot using DAB substrate (Sigma, USA).

Amino acid sequence analysis revealed that P32 protein possesses putative transmembrane domains as reported previously (Carn et al., 1994; Heine et al., 1999). The presence of transmembrane domain in the target protein sequence may result in low or absence of expression. Therefore, primers specific to truncated P32 gene were designed. These primers sequences were appended with different restriction enzymes viz. Nco I and Xho I restriction sites in order to facilitate directional cloning. After infection with GTPV Uttarkashi strain (P60), cytopathic effect (CPE) was observed till 6 dpi. Using extracted genomic DNA, PCR reaction using suitable designed primers listed in Table 1 resulted in amplification of respective F13L and P32genes $(\sim 1130$ bp and $\sim 770$ bp, respectively) as observed on $1.5 \%$ agarose gel electrophoresis (Fig. 1, panel A and B). The purified PCR products and pET-33b(+) vector were double digested with Nco I and Xho I enzymes for directional cloning. Each positive clone showed specific band size in colony PCR. Recombinant plasmids isolated from positive clones after digestion with $\mathrm{NcO}$ I and
Xho I enzymes showed a single linear band of high molecular weight corresponding to vector DNA and bands of respective sizes. The positive recombinant plasmids were used for transformation into E. coli expression cells for the purpose of expression. Following induction using $1 \mathrm{mM}$ IPTG, the induced cultures were harvested at $6 \mathrm{~h}$ post-induction. The harvested samples were analyzed in SDSPAGE by comparison of protein profile of recombinant clones with the control (noninduced E. coli cells). In induced samples, proteins with $\sim 41 \mathrm{kDa}$ and $\sim 30 \mathrm{kDa}$ were observed in case of F13L and P32 proteins, respectively after $6 \mathrm{~h}$ post induction (Fig. 2, panel $\mathrm{A}$ and $\mathrm{B}$ ). In un-induced cultures, no additional band of protein was noticed. Recombinant proteins were expressed in $E$. coli as C-terminal His-tagged proteins. They lacked any other fusion tag from pET-33b(+) vector. In order to use these proteins for further diagnostic or prophylactic purposes, it was necessary to purify them from the rest of the contaminating E. coli proteins. Therefore, Ni-NTA affinity columns were used in the study for affinity purification of recombinant proteins as these proteins are tagged with histidine tag at $\mathrm{C}$-terminus. Histidine tag is poorly immunogenic, and at $\mathrm{pH} 8.0$, it is small, uncharged, and therefore does not generally affect secretion, compartmentalization, or folding of the fusion proteins within the cell (Sambrook and Russell, 2001). The solubility analysis revealed that $\mathrm{F} 13 \mathrm{~L}$ protein was found in insoluble fraction which was solubilized in binding buffer containing $8 \mathrm{M}$ urea, and purified by affinity chromatography under denaturing/renaturing conditions, before final elution using $300 \mathrm{mM}$ imidazole buffer (Fig. 2, panel A). However, due to the difficulty in solubilizing $\mathrm{P} 32$ protein in $8 \mathrm{M}$ urea or guanidine hydrochloride, purification was achieved by passive elution of protein from the 10\% SDS-polyacrylmide gel (Fig. 2, panel B). Purification by passive elution method, 
although slow and cumbersome, results in high level of purity. Immunodominant P32 protein, expressed in prokaryotic system has proven to be problematic during purification (Carn et al., 1994; Heine et al., 1999). The pooled protein fractions were dialysed and concentration was found to be $0.1 \mathrm{mg} / \mathrm{ml}$ of elute for both the proteins. The recombinant proteins resolved in SDS-PAGE were transferred on to a nitrocellulose membrane and specificity of GTPV recombinant proteins expression was confirmed using anti-GTPV serum. An intensive color reaction was observed with the proteins sizes corresponding to expressed proteins with specific sizes (Fig. 3, panel A and B).

Table.1 Designed primers for expression of F13L and P32 proteins of GTPV

\begin{tabular}{|c|c|c|c|c|}
\hline Gene & Primer ID & Primer sequence (5'-3') & $\begin{array}{l}\text { Target } \\
\text { region }\end{array}$ & $\begin{array}{c}\text { Amplicon } \\
\text { size (bp) }\end{array}$ \\
\hline \multirow[t]{2}{*}{ F13L } & CaPV-F13LF & gtgCCATGGGCATGTGGTCCTTATTTTTTTC & \multirow{2}{*}{$\begin{array}{l}{ }_{1} \mathrm{M}- \\
\mathrm{L}_{370}\end{array}$} & \multirow[t]{2}{*}{1130} \\
\hline & CaPV-F13L R & gtaCTCGAGCAGCACTGTATTTTTTTTGTCTG & & \\
\hline \multirow[t]{2}{*}{ P32 } & $\mathrm{CaPV}-\mathrm{P} 32_{\mathrm{Tr}} \mathrm{F}$ & gtgCCATGGTTCCAGAATTAAAAAGTGGC & \multirow{2}{*}{$\begin{array}{l}{ }_{20} \mathrm{~V}- \\
\mathrm{S}_{270}\end{array}$} & \multirow[t]{2}{*}{770} \\
\hline & $\mathrm{CaPV}-\mathrm{P} 32_{\mathrm{Tr}} \mathrm{R}$ & gtgCTCGAGAGAAAAATCAGGAAATCTATG & & \\
\hline
\end{tabular}

Fig.1 PCR amplification of F13L and P32 genes

Panel A: Amplification of F13L gene by PCR. Lane M: DNA standard marker; Lane 1, 2: PCR amplicon of F13L gene (1130 bp); Lane 3: Negative control.

Panel B: Amplification of P32 gene by PCR. Lane M: DNA standard marker; Lane 1, 2: PCR amplicon of P32 gene (770 bp); Lane 3: Negative control.

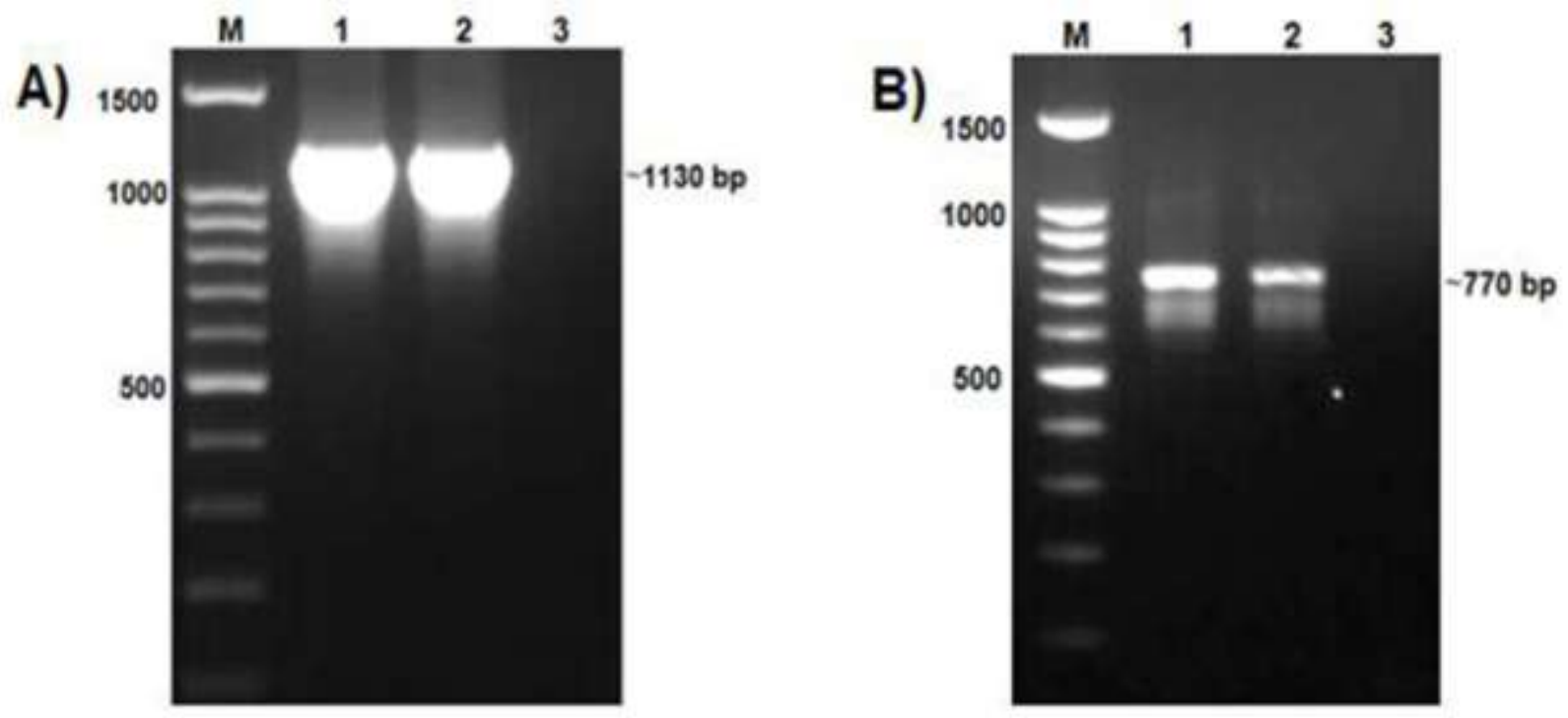

Fig.2 Expression and purification of recombinant F13L and P32 proteins of GTPV 
Panel A: Expression and purification of recombinant F13L protein. Lane M: Protein marker; Lane C: Un-induced $E$. coli cell lysate; Lanes 2 and 3: Induced $E$. coli cell lysate showing recombinant F13L protein ( $41 \mathrm{kDa})$; Lanes P1, P2: Ni-NTA chromatography purified fractions of recombinant F13L protein.

Panel B: Expression and purification of recombinant P32 protein. Lane M: Protein marker; Lane C: Un-induced $E$. coli cell lysate; Lanes 2 and 3: Induced E. coli cell lysate showing recombinant P32 protein ( 30 kDa); Lanes P1, P2: Passively eluted purified fractions of recombinant P32 protein.
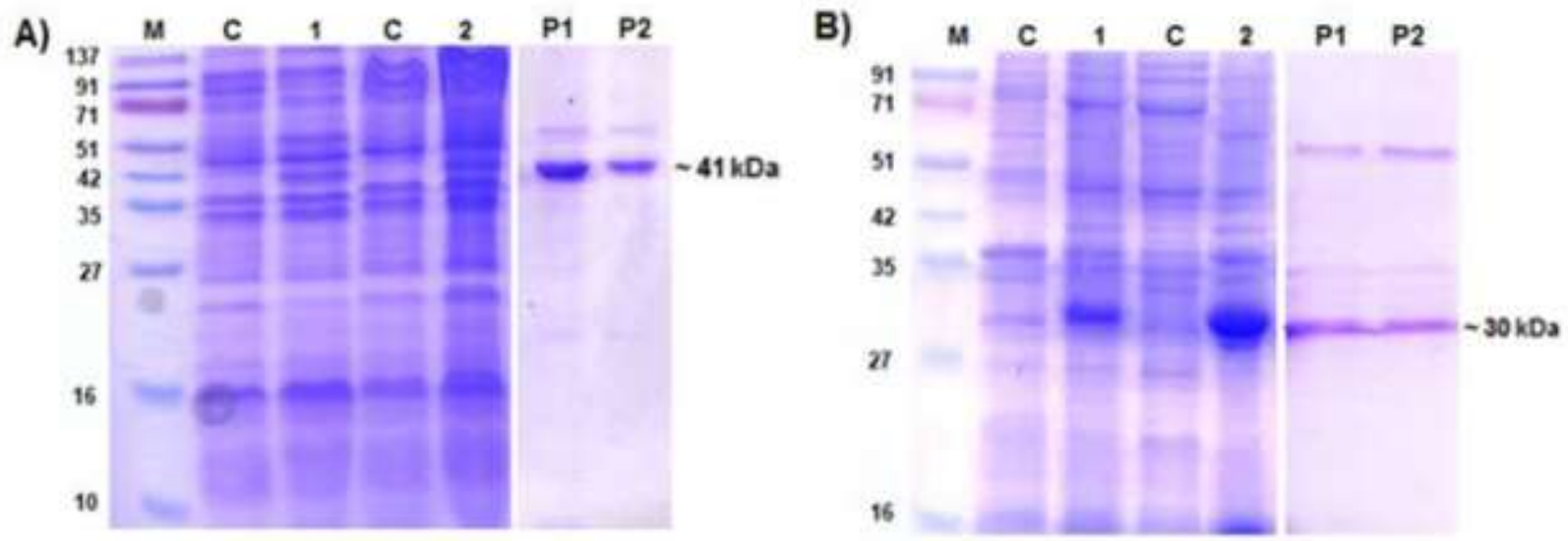

Fig.3 Western blot of recombinant F13L and P32 proteins of GTPV

Panel A: Western blot of recombinant F13L protein with anti-GTPV serum. Lane-M:Protein marker; Lanes 1 and 2: Induced $E$. coli cell lysate showing recombinant F13L protein $(\sim 41 \mathrm{kDa})$.

Panel B: Western blot of recombinant P32 protein with anti-GTPV serum. Lane-M:Protein marker; Lanes 1 and 2: Induced E. coli cell lysate showing recombinant P32 protein $(\sim 30 \mathrm{kDa})$.

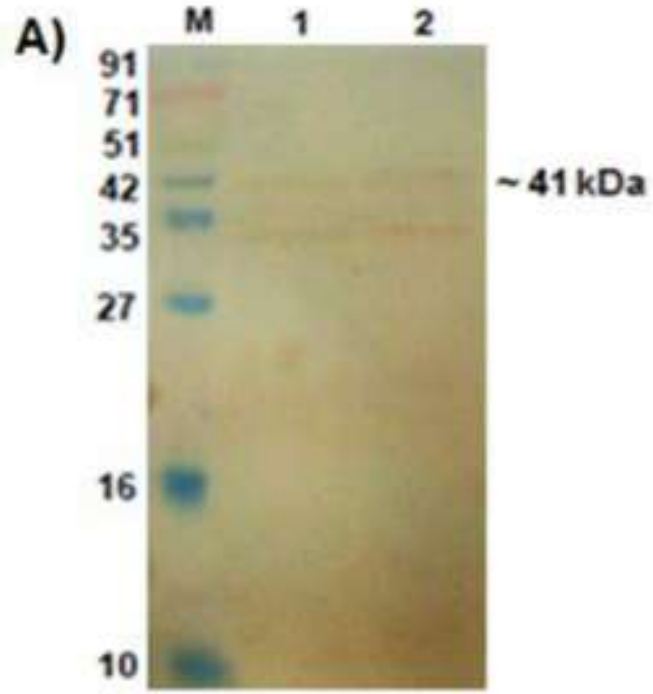

In poxviruses, IMV form is released by lysis of infected cells and thought to play the major role in the host-to-host transmission of virus, while EEV form is released by budding and is responsible for the spread within the host

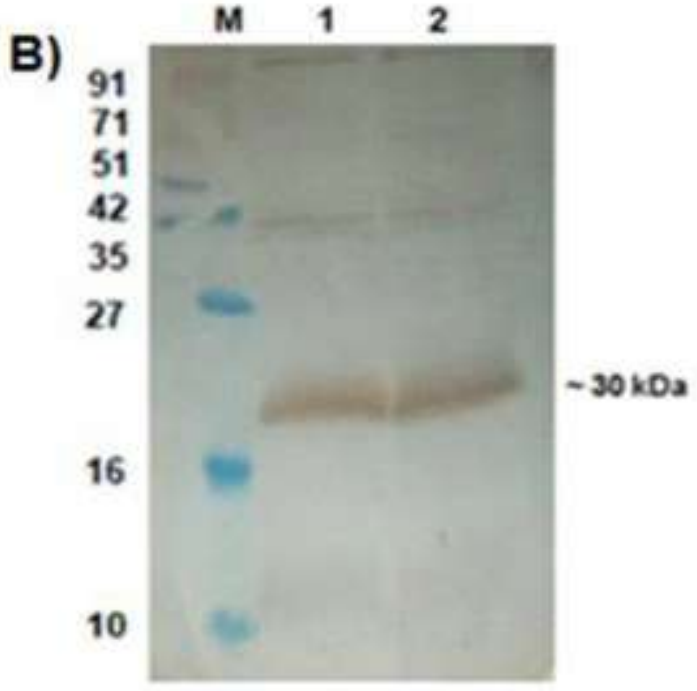

(Condit et al., 2006). F13L is nonglycosylated, abundant EEV protein.B2L protein of ORFV (homolog of VACV F13L) has been proven to be immunogenic in laboratory animals (Yogisharadhya et al., 
2017). P32 protein is homolog of immunodominant $\mathrm{H} 3 \mathrm{~L}$ protein of VACV (Chand, 1992). It mediates VACV adsorption to cell surface heparan sulfate (Lin et al., 2000). Immunogenicity of VACV H3L (Davies et al., 2005) and BPXV H3L (Kumar et al., 2016) has also been evaluated in laboratory animals. P32 protein has been expressed in prokaryotic/eukarayotic expression sytems and evaluated for diagnostic potential (Carn et al., 1994; Heine et al., 1999; Bhanot et al., 2009; Venkatesan et al., 2018). However, problems associated with expression level of the full length P32 antigen in E. coli due to toxicity of the expressed hydrophobic product, purification and stability of expressed protein are considered as limitations (Carn et al., 1994; Heine et al., 1999; Venkatesan et al., 2018). Therefore, a cocktail ELISA based on recombinant proteins either individually or as combined IMV and EEV proteins may serve as potential diagnostic antigen for serodiagnosis of capripoxviruses.

\section{Acknowledgements}

The authors thank the Director, Indian Veterinary Research Institute for providing necessary facilities to carry out this work and the staff of Pox virus laboratory, IVRI, Mukteswar, for their valuable and timely help in carrying out this work.

\section{References}

Babiuk, S., Wallace, D. B., Smith, S. J., Bowden, T. R., Dalman, B., Parkyn, G., Copps, J. and Boyle, D. B. 2009. Detection of antibodies against capripoxviruses using an inactivated sheeppox virus ELISA. Transbound. Emerg. Dis. 56(4): 132-141.

Bhanot, V., Balamurugan, V., Bhanuprakash, V., Venkatesan, G., Sen, A., Yadav, V., Yogisharadhya, R. and Singh, R.K.
2009. Expression of P32 protein of goatpox virus in Pichiapastoris and its potential use as a diagnostic antigen in ELISA. J. Virol. Methods162(1-2): 251257.

Bhanuprakash, V., Hosamani, M. and Singh, R. K. 2011. Prospects of control and eradication of capripox from the Indian subcontinent: a perspective. Antiviral Res. 91(3): 225-232.

Bowden, T. R., Coupar, B. E., Babiuk, S.L., White, J. R., Boyd, V., Duch, C. J., Shiell, B. J., Ueda, N., Parkyn, G. R., Copps, J. S. and Boyle, D. B. 2009. Detection of antibodies specific for sheeppox and goatpox viruses using recombinant capripoxvirus antigens in an indirect enzyme-linked immunosorbent assay. J. Virol. Methods 161(1): 19-29.

Chung C. S., Chen C. H., Ho M. Y., Huang C. Y., Liao C. L. and Chang W. 2006. Vaccinia virus proteome: identification of proteins in vaccinia virus intracellular mature virion particles. J. Virol. 80(5): 2127-2140.

Condit, R.C., Moussatche, N. andTraktman, P. 2006. In a nutshell: structure and assembly of the vaccinia virion. Adv. Virus Res. 66: 31-124.

Davies, D. H., McCausland, M. M., Valdez, C., Huynh, D., Hernandez, J. E., Mu, Y., Hirst, S., Villarreal, L., Felgner, P. L. and Crotty, S. 2005. Vaccinia virus $\mathrm{H} 3 \mathrm{~L}$ envelope protein is a major target of neutralizing antibodies in humans and elicits protection against lethal challenge in mice. J. Virol.79(18): 11724-11733.

Kumar, A., Yogisharadhya, R., Venkatesan, G., Bhanuprakash, V., Pandey, A. B. and Shivachandra, S. B.2017. Coadministration of recombinant major envelope proteins (rA27L and $\mathrm{rH} 3 \mathrm{~L}$ ) of buffalopox virus provides enhanced immunogenicity and protective efficacy 
in animal models. Antiviral Res. 141: 174-178.

Madhavan, A., Venkatesan, G. and Kumar,A. 2016.Capripoxviruses of small ruminants: current updates and future perspectives. Asian J. Anim. Vet. Adv. 11: 757-770.

Mirzaie, K., Barani, S. M. and Bokaie, S. 2015. A review of sheep pox and goat pox: perspective of their control and eradication in Iran. J. Adv. Vet. Anim. Res. 2(4): 373-381.

Lin, C. L., Chung, C. S., Heine, H. G. and Chang, W. 2000. Vaccinia virus envelope $\mathrm{H} 3 \mathrm{~L}$ protein binds to cell surface heparan sulfate and is important for intracellular mature virion morphogenesis and virus infection in vitro and in vivo. J. Virol. 74(7):33533365 .

Sambrook, J. and Russell, D. W. 2001. Molecular Cloning: A laboratory manual. Volume 3. $3^{\text {rd }}$ edn. New York, NY:Cold Spring Harbor Laboratory Press.

Sharma, B., Negi, B. S., Yadav, M. P., Shankar, H. and Pandey, A. B. 1988. Application of ELISA in the detection of goat pox antigen and antibody. Acta Virol. 32: 65-69.
Tuppurainen, E. S. M., Venter, E. H., Shisler, J. L., Gari, G., Mekonnen, G. A., Juleff, N., Lyons, N. A., De Clercq, K., Upton, C., Bowden, T. R., Babiuk, S. and Babiuk, L. 2017. Review: Capripoxvirus diseases: current status and opportunities for control. Transbound. Emerg. Dis. 64(3): 729745.

Venkatesan, G., Teli, M. K., Sankar, M., Kumar, A., Dashprakash, M., Arya, S., Madhavan, A., Ramakrisnan, M. A. and Pandey, A. B. 2018. Expression and evaluation of recombinant $\mathrm{P} 32$ protein based ELISA for sero-diagnostic potential of capripox in sheep and goats. Mol. Cell. Probes 37: 48-54.

Yogisharadhya, R., Kumar, A., Ramappa, R., Venkatesan, G., Bhanuprakash, V. and Shivachandra, S. B.2017.Functional characterization of recombinant major envelope protein (rB2L) of orf virus. Arch. Virol. 162(4):953-962.

Yogisharadhya, R., Kumar, A., Bhanuprakash, V. and Shivachandra, S. B. 2018. Evaluation of a recombinant major envelope protein (F1L) based indirect- ELISA for sero-diagnosis of orf in sheep and goats. J. Virol. Methods 261: 112-120.

\section{How to cite this article:}

Amit Kumar, Gnanavel Venkatesan, Anand Kushwaha, P. Sasi Kumar, M.A. Ramakrishnan and Pronab Dhar. 2019. Expression and Purification of Recombinant Immunogenic Proteins of Goat Poxvirus in Prokaryotic System. Int.J.Curr.Microbiol.App.Sci. 8(01): 1984-1990. doi: https://doi.org/10.20546/ijcmas.2019.801.208 